Sustainable Forward

Operating Base Nuclear Power Evaluation (Relationship Mapping System) Users' Manual

Version 1.0

January 2012

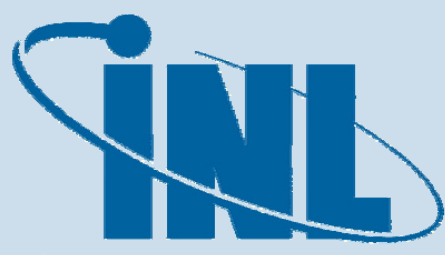

Idaho National Laboratory 


\section{DISCLAIMER}

This information was prepared as an account of work sponsored by an agency of the U.S. Government. Neither the U.S. Government nor any agency thereof, nor any of their employees, makes any warranty, expressed or implied, or assumes any legal liability or responsibility for the accuracy, completeness, or usefulness, of any information, apparatus, product, or process disclosed, or represents that its use would not infringe privately owned rights. References herein to any specific commercial product, process, or service by trade name, trade mark, manufacturer, or otherwise, does not necessarily constitute or imply its endorsement, recommendation, or favoring by the U.S. Government or any agency thereof. The views and opinions of authors expressed herein do not necessarily state or reflect those of the U.S. Government or any agency thereof. 


\title{
Sustainable Forward Operating Base Nuclear Power Evaluation (Relationship Mapping System) Users' Manual
}

Version 1.0

January 2012

\author{
Idaho National Laboratory \\ Systems Engineering Department \\ Idaho Falls, Idaho 83415
}

http://www.inl.gov

Prepared for the

Defense Advanced Research Projects Agency and for the

U.S. Department of Energy

Under DOE Idaho Operations Office

Contract DE-AC07-05ID14517 



\section{ABSTRACT}

The Sustainable Forward Operating Base (FOB) Nuclear Power Evaluation was developed by the Idaho National Laboratory Systems Engineering Department to support the Defense Advanced Research Projects Agency (DARPA) in assessing and demonstrating the viability of deploying small-scale reactors in support of military operations in theatre. This document provides a brief explanation of how to access and use the Sustainable FOB Nuclear Power Evaluation utility to view assessment results as input into developing and integrating the program elements needed to create a successful demonstration. 


\section{CONTENTS}

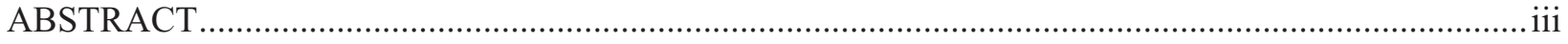

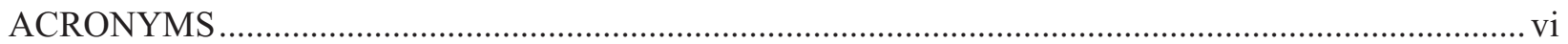

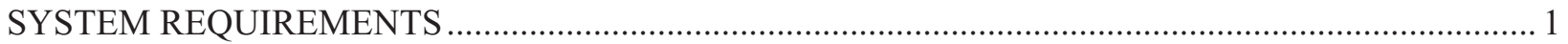

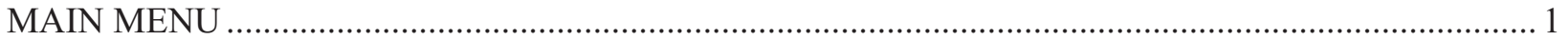

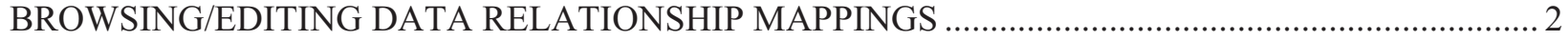

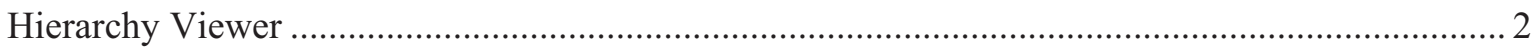

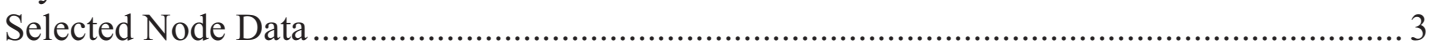

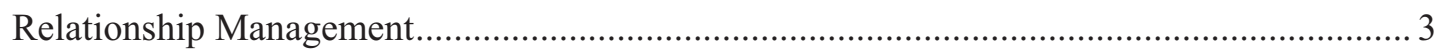

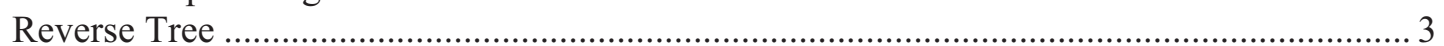

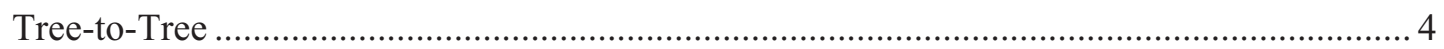

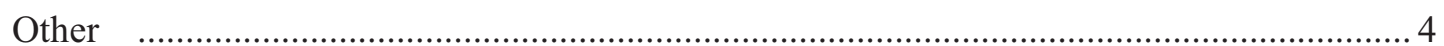

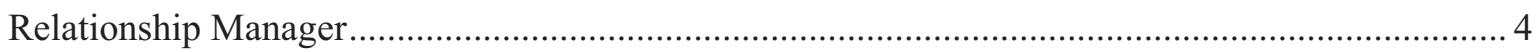

ADDING, EDITING, OR DELETING ELEMENT DATA.............................................................. 5

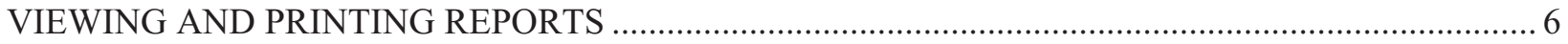




\section{ACRONYMS}

DARPA Defense Advanced Research Projects Agency

FOB Forward Operating Base

INL Idaho National Laboratory

WBS Work Breakdown Structure 


\section{Sustainable Forward Operating Base Nuclear Power Evaluation User's Manual}

The Sustainable Forward Operating Base (FOB) Nuclear Power Evaluation was developed by the Idaho National Laboratory (INL) Systems Engineering Department to support the Defense Advanced Research Projects Agency (DARPA) in assessing and demonstrating the viability of deploying small-scale reactors in support of military operations in theatre. The evaluation identifies and integrates the key program elements needed to create a successful demonstration, and assesses safety and security challenges in a tactical context, such as hostile threats, personnel proximity, and operational constraints. As additional issues or changes are identified, they can be captured in the system with the respective impacts and resolutions maintained for future reference.

This document provides a brief explanation of how to access and use the Sustainable FOB Nuclear Power Evaluation utility to view assessment results as input into developing and integrating the program elements needed to create a successful demonstration.

\section{SYSTEM REQUIREMENTS}

The Sustainable FOB Nuclear Power Evaluation utility runs in a Microsoft Office environment using Microsoft Access 2007 or better.

If users do not have a copy of Microsoft Access 2007, or better, it is possible to run the utility by installing Microsoft Office Access 2007 Runtime. The installation file is included on the CD-ROM provided to DARPA. Alternatively, Microsoft Office Access 2007 Runtime can be downloaded directly from Microsoft's Download Center at:

http://www.microsoft.com/download/en/details.aspx?displaylang=en\&id=4438

\section{MAIN MENU}

The MAIN MENU provides user access to Evaluation components. These include:

- Browse/Edit Relationship Mappings

- Add/Edit or Delete Element Data

- Report

- Quit Application.

Click on the box to the left of the desired option to enter that area of the utility.

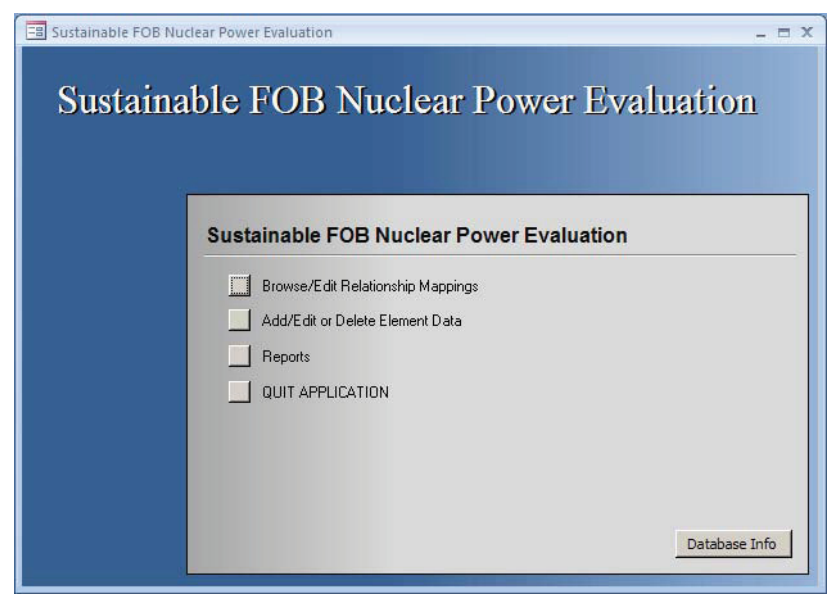




\section{BROWSING/EDITING DATA RELATIONSHIP MAPPINGS}

Three options are provided to Browse/Edit Data Relationship Mappings. These are:

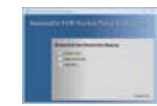

- Hierarchy Viewer

- Relationship Manager

- Return to MAIN MENU

Click on the box to the left of the desired option to enter that area of the utility. A more detailed description of each option is provided below.

\section{Hierarchy Viewer}

The Hierarchy Viewer is divided into two regions: the hierarchy viewer pane (on the left) and an information/data manipulation pane (on the right). Information regarding items selected in the left pane is displayed in the right pane according to the type of view (tab) chosen. Using the various views provided, users can view and establish relationships between project elements. The various views are described in detail below.

To view information, users must first select the type of element to be displayed.

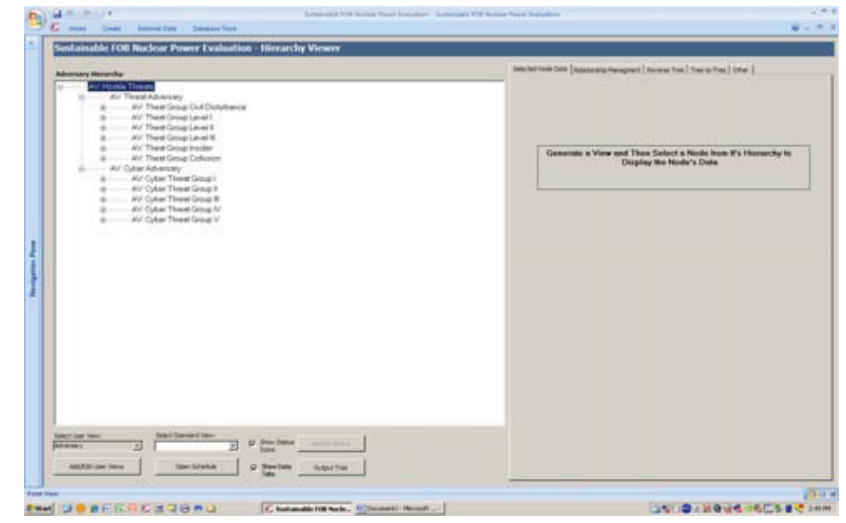

- Click on the down arrow to the right of the Select User View data field

- Scroll down to find the desired element type

- Click on the desired element to generate the data tree in the Hierarchy Viewer window.

Eight custom views are available, including:

- Adversary Hierarch

- Concept Description Hierarchy

- Concept of Employment Hierarchy

- Hostile Threat Outcomes Hierarchy

- Organizations Hierarchy

- Requirements Hierarchy

- Threats Hierarchy

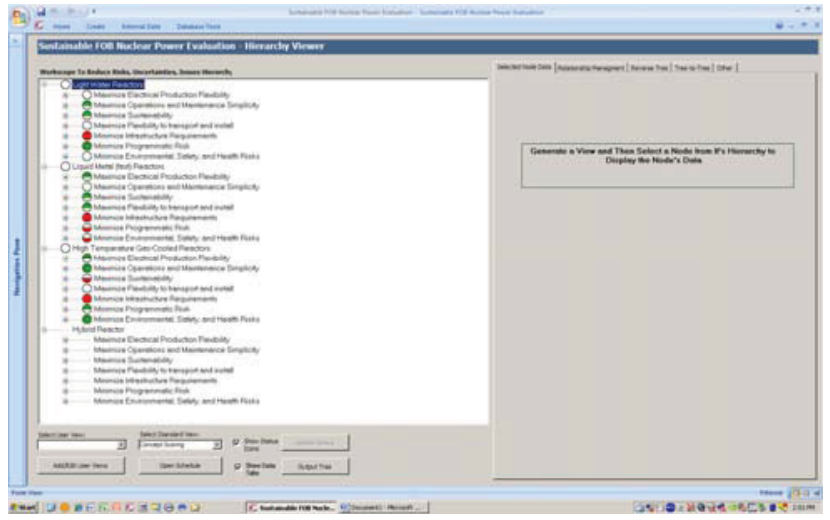

- Workscope to Reduce Risks, Uncertainties, Issues Hierarchy.

Standard views, such as Concept Scoring, can also be selected from the Select Standard View data field. 


\section{Selected Node Data}

The Selected Node Data view displays information specific to the element selected in the left pane. The information includes:

- Title

- Description

- Category

- Subcategory

- Notes.

\section{Relationship Management}

The Relationship Management view allows users to establish relationships between program elements. This is accomplished by selecting an element from the right pane and dropping it onto the desired "parent" element in the left pane, as follows:

- Click on the down arrow to the right of the Select Element Type data field and scroll down to find the desired element type

- Click on the desired element to display all available elements in the Edit Node window.

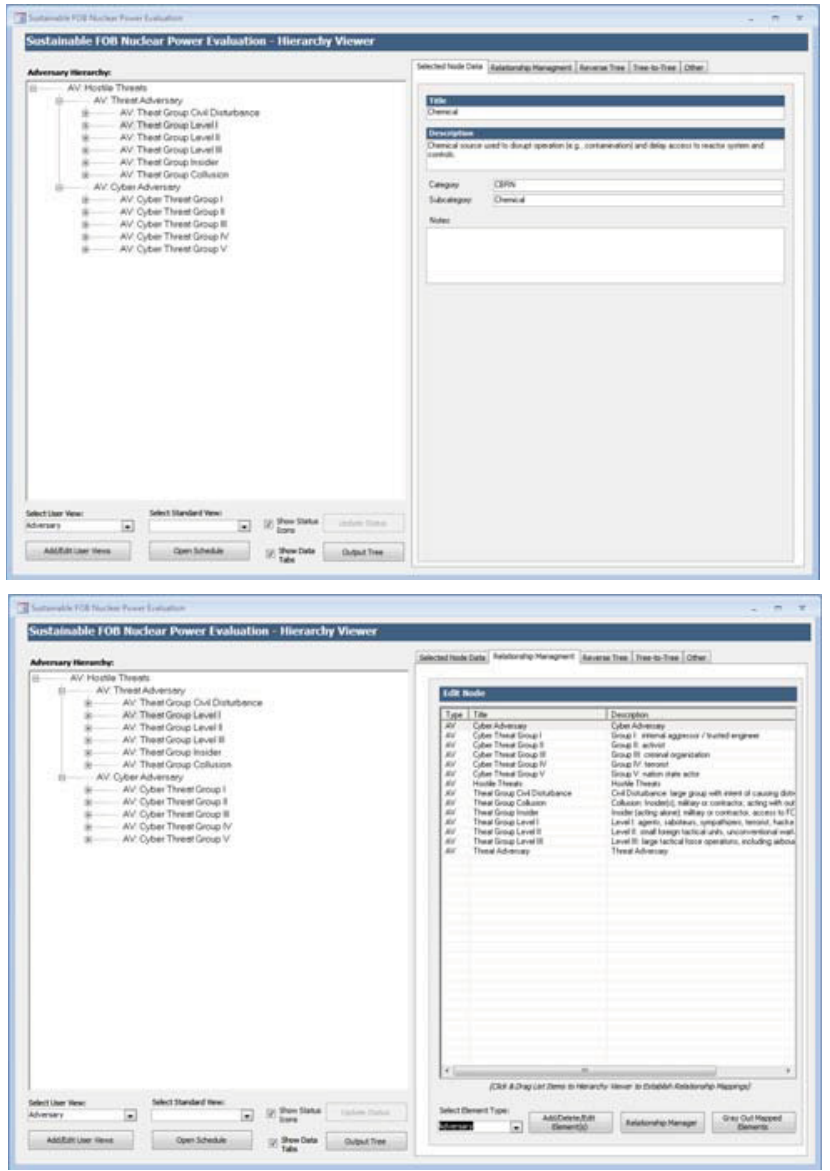

- Click and drag the desired item from the right pane and drop in onto the desired parent node in the left pane.

Under this view, relationships are always established as child (right pane) to parent (left pane).

Clicking the Add/Delete/Edit Elements(s), Relationship Manage, and Gray Out Mapped Elements buttons will open additional windows that provide additional relationship management capabilities. These windows are described in greater detail below.

\section{Reverse Tree}

The Reverse Tree view allows users to select a node from the standard (parent-to-child) relationship tree in the left pane and view a reversed (child-to-parent) relationship tree of that node in the right pane.

The Reverse Tree View and Standard Tree View buttons at the bottom of the right pane provide the capability for users to toggle between the child-toparent and parent-to-child views, respectively, for the selected node.

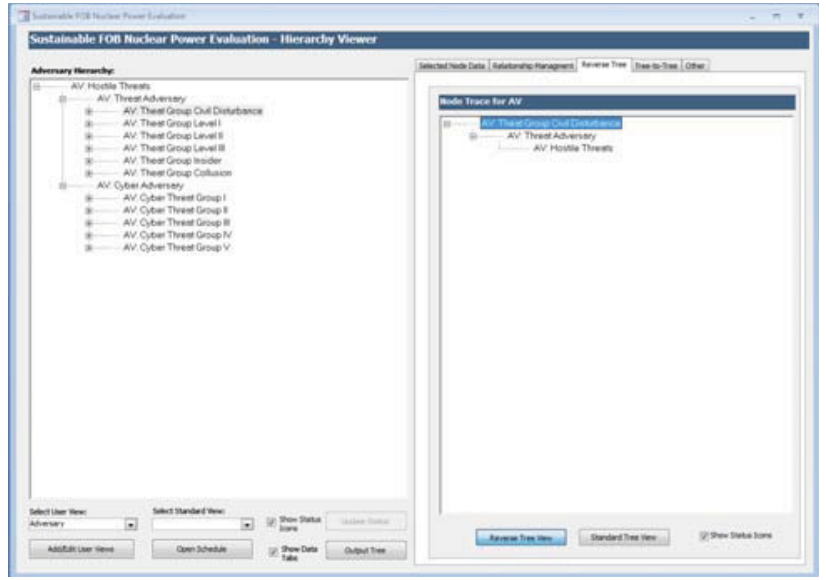




\section{Tree-to-Tree}

This Tree-to-Tree view allows users to simultaneously view and compare the relationship trees of two separate hierarchies, as follows:

- Click on the down arrow to the right of the Select User View data field in either the left or right pane and scroll down to find the desired element type

- Click on the desired item to display the parent-child relationships.

- Repeat steps in the other pane to select a different element for display and comparison.

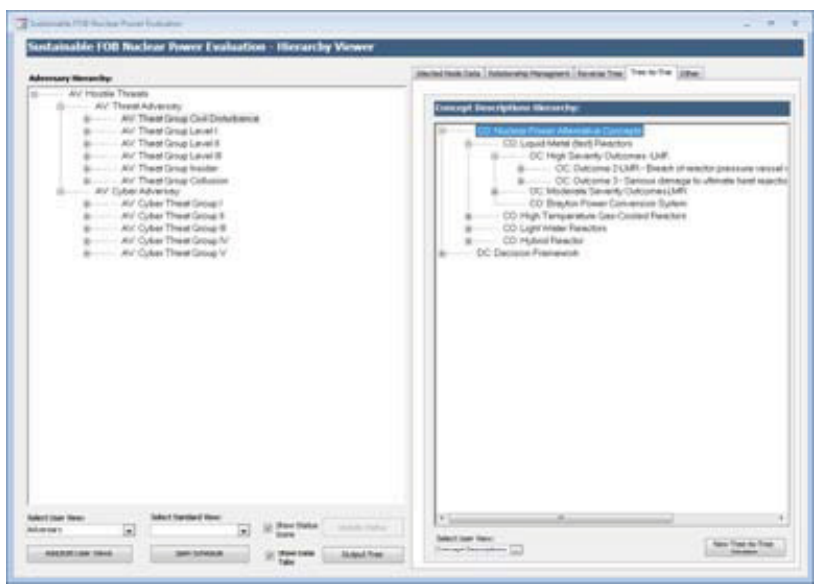

\section{Other}

The Other view provides users with the unique ID of the selected node. Additionally, it allows users the option (not recommended) to delete all unmapped elements from the database.

\section{Relationship Manager}

The Relationship Manager utility allows users to view system elements in the upper window and view/establish parent-child relationships in the lower window. The utility functions as follows:

- Click on the down arrow to the right of the Select Element Filter data field and scroll down to find the desired element type

- Click on the desired element type and all available elements for that type will be displayed in the upper data window.

- Click on a desired item in the upper window to display the parent-child relationships in the lower data window.

The Immediate Parent Mappings tab displays the selected element's immediate parents, while the Immediate Child Mappings tab displays that element's children. 

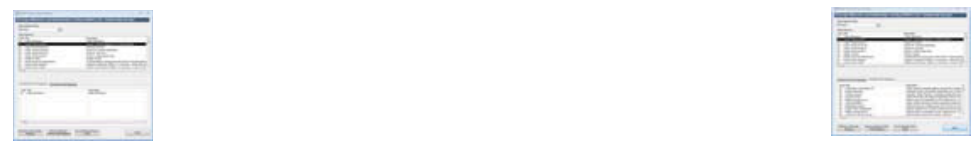

Other buttons allow users to Add New Parent [or Child] Node Mappings (depending on the mappings tab being displayed), Remove Selected Parent [or Child] Node Mappings, or Go to a Selected Parent [or Child] Node.

Adding a new Parent or Child Node Mapping is accomplished as follows:

- Click on the Add New Parent [or Child] Node Mapping button at the bottom left of the Relationship Manager window to display the Add Node Mapping window.

- Click on the down arrow to the right of the Select Parent [or Child] Element Filter data field

- Scroll down to find the desired element type to be mapped

- Click on the desired item to display the available elements in the lower pane

- Highlight the item to be mapped

- Click the Add Selected Item as Parent [or Child] button to establish the relationship.

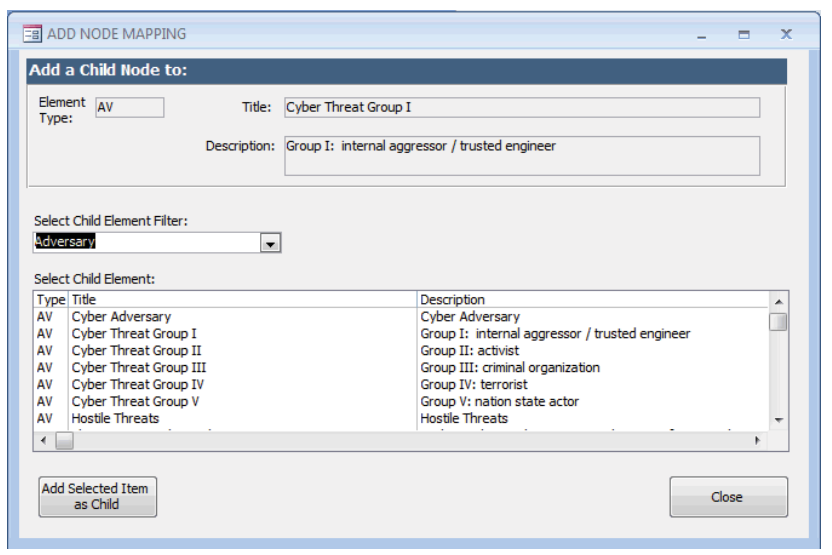

\section{ADDING, EDITING, OR DELETING ELEMENT DATA}

The Adding, Editing, or Deleting Element Data feature is not available in this version of the Sustainable FOB Nuclear Power Evaluation utility. All applicable data has been pre-populated to facilitate the easy review and assessment of nuclear energy feasibility, and is not intended to be edited. Development of this capability is possible and may be consider in the event future versions and ongoing support to DARPA by the INL. 


\section{VIEWING AND PRINTING REPORTS}

The Reports feature is not available in this version of the Sustainable FOB Nuclear Power Evaluation utility. Development of this capability is possible and may be consider in the event future versions and ongoing support to DARPA by the INL. 